\title{
NOTAS SOBRE A AGRICULTURA NA EVOLUÇÃO DO PENSAMENTO ECONÔMICO
}

\section{ARTIGO ORIGINAL}

FERRAZ, Carlos Alberto Leitão ${ }^{1}$

FERRAZ, Carlos Alberto Leitão. Notas sobre a agricultura na evolução do pensamento econômico. Revista Científica Multidisciplinar Núcleo do Conhecimento. Ano 05, Ed. 08, Vol. 16, pp. 107-125. Agosto de 2020. ISSN: 24480959, Link de acesso: https://www.nucleodoconhecimento.com.br/meioambiente/agricultura-na-evolucao

\section{RESUMO}

O artigo analisa a agricultura na evolução do pensamento econômico. Evidenciando as diversas especificidades e questões do setor agrícola conforme a visão das principais escolas econômicas no decorrer da evolução da teoria econômica. Como cada uma das correntes econômicas interpretou o papel deste setor no aspecto mais amplo da economia. Busca-se demonstrar sinteticamente como a história do pensamento econômico incorporou teoricamente, nas suas principais vertentes, as mudanças que ocorreram nas funções da agricultura ao longo do seu desenvolvimento. Trata-se de estudo de revisão bibliográfica, apoiando-se, sempre que possível, nos escritos originais dos principais autores de cada corrente econômica analisada. O texto conclui que, ao longo da evolução da ciência econômica, a agricultura sempre se manteve presente nos principais estudos sobre o pensamento econômico, de maneira diferenciada, acompanhando o seu papel na economia no transcorrer de seu desenvolvimento.

\footnotetext{
${ }^{1}$ Economista e professor da UNEB, Doutor em Desenvolvimento Regional e Urbano (UNIFACS).
} 
Palavras-chave: Evolução, pensamento, econômico, agricultura.

\section{INTRODUÇÃO}

Nos primórdios da humanidade, a atividade econômica dos homens se resumia à coleta, à caça e à pesca. Os homens viviam em bandos, ou seja, eram gregários. $\mathrm{O}$ trabalho de caça poderia resultar na presa e/ou abate de um animal que permitisse alimentar os componentes de um grupo por dias ou mesmo por semanas ou então resultar em insucesso. De forma que o grupo não conseguia o alimento necessário a sua subsistência. O mesmo se pode dizer da pesca, dada ainda os instrumentos rudimentares para a sua efetivação. A coleta, por sua vez, realizada pelas mulheres, obtinha sucesso no seu objetivo com o apanhe de vegetais suficientes para suprir o grupo durante alguns dias.

Desta forma, o homem mantém, embora predatória, uma estreita relação com a natureza. Porém, essa relação é de dependência. Pois, é ela que the supri os alimentos necessários a sua existência.

A existência nômade imposta pelas mudanças naturais começa lentamente a ser modificada. Aos poucos, o homem pela observação passou a intervir na reprodução e seleção de animais e vegetais que Ihe servissem de alimentos. Esse domínio inicial da natureza e a domesticação de animais, durante o período neolítico, fez surgir a agricultura. A partir daí, o homem passará de nômade a sedentário, passará a controlar sua própria oferta de alimentos.

A expansão da agricultura levará o homem a fixar-se em determinada área e a apropriar-se do solo, Assim, emergem e consolidam-se a divisão social das atividades laboriosas, a divisão da sociedade em classes sociais e o estado.

No entanto, é com o advento da Primeira Revolução Industrial ou Revolução Industrial Inglesa que o homem quebra a dependência das forças naturais para efetivar seu trabalho produtivo. Nos períodos que precederam a primeira revolução industrial os mecanismos e máquinas utilizadas no processo produtivo dependiam na sua 
propulsão das forças da natureza, como rios e ventos, da força dos animais ou da força humana. Mas a introdução da máquina a vapor por James Watt transforma radicalmente esta dependência: o vapor da água passa a ser fonte de força motriz. Isto possibilitou determinar a duração dos ciclos de produção e torná- los contínuos e adequá-los as oscilações da demanda.

Mas não foi só no aspecto do avanço tecnológico que a revolução industrial perpetrou mudanças radicais. A partir dela a finalidade da atividade econômica passa a ser obter a ampliação do capital pela produção de mercadorias e não produzir mercadorias para atender as necessidades humanas. Assim, como o capital agrícola e o capital comercial se subordinaram ao capital industrial, este último passou, a partir de determinado momento, a subordina-se ao capital financeiro.

Assim, este texto pretende demonstrar sinteticamente como a história do pensamento econômico incorporou teoricamente, nas suas principais vertentes, as mudanças que ocorreram nas funções da agricultura ao longo do seu desenvolvimento. Para isso, este artigo, após esta introdução, estrutura-se nas seguintes seções: agricultura na antiguidade, agricultura no feudalismo, a emergência da economia voltada para o mercado, agricultura como única fonte do excedente econômico e da riqueza, o desenvolvimento agrícola nos clássicos: Smith, Ricardo e Malthus, o papel subordinado da agricultura, a abordagem neoclássica: o fim da agricultura como setor específico na análise econômica, do enfoque agrícola ao enfoque agrário e as considerações finais.

\section{A AGRICULTURA NA ANTIGUIDADE}

A análise da agricultura pela visão econômica no período grego deve ser entendida de acordo com os parâmetros filosóficos que orientavam a ordem econômica da época: I - Predomínio do geral sobre o particular, ou seja, o bem estar individual subordinado ao bem estar coletivo; II - Igualdade ética, neste aspecto o estado grego ideal seria composto de determinado número estável de habitantes, tornando mais fácil a preservação da ordem social; e III - Desprezo pela riqueza, assim o aspecto 
essencial do ser humano é a sua alma, seguida pelos cuidados corporais e, por fim, a riqueza.

O pensamento filosófico na Grécia irá influenciar sobremaneira as visões econômicas que surgem à época. A corrente individualista que contrapõe as razões do estado e as do indivíduo, critica o desprezo pela riqueza e inicia a reabilitação da atividade laboral. Outra vertente individualista, cujo principal expoente foi Aristóteles, faz críticas ao comunismo de Platão. Porém, mesmo discordando de Platão, quanto à forma de organização social preconizada por aquele pensador, Aristóteles aproxima-se dele em relação ao desprezo a propriedade privada e a liberdade individual. Esta visão da economia propõe o controle demográfico para manter o predomínio do estado sobre o indivíduo. Além dessas duas visões da economia citadas, houve a corrente socialista que teve em Platão seu principal formulador. Ele preconiza a estruturação de um estado ideal, onde predomine a justiça e o cidadão dedique o máximo de tempo à atividade política e aos estudos de filosofia. Desta forma, as matizes econômicas devem ser restritas ao mínimo que se faça necessário. O trabalho manual não é contemplado nesta estrutura socialista, comerciante e artesão são desconsiderados e o agricultor, por sua vez, é relevante para o sistema.

Assim, na sua fase embrionária ou pré-científica, a ciência econômica atribuía ao setor agrícola uma importância de destaque na economia. A par disso, via a agricultura como uma atividade que se harmonizava com a natureza. Neste contexto, no pensamento econômico de então, a agricultura era, para todos os efeitos, uma atividade econômica central e eticamente superior. (CORAZZA e MARTINELLI JR., 2002, p. 11).

\section{A AGRICULTURA NO FEUDALISMO}

A economia medieval pode ser desdobrada em dois períodos econômicos. Um que compreende os séculos $\mathrm{V}$ ao $\mathrm{XI}$, onde ocorrem as invasões dos povos bárbaros, decadência e extinção da antiga economia e a fragmentação econômica do feudalismo, então em sua plenitude. O intercâmbio comercial, quando ocorre, se dá na própria localidade, sendo raras as trocas realizadas fora dos domínios do feudo. 0 outro período se estende do século XI ao XIV que representa uma fase de ascensão comercial. A partir do século XI, depois de uma etapa decadente, ressurgem as trocas 
e o comércio. Concomitantemente, expandem-se os ofícios especializados, a divisão do trabalho eleva a produção, o mercado amplia-se.

Durante o transcurso medieval a igreja católica exerce significativa influência na vida e nas ideias de toda a população. No plano das ideias econômicas, esta ciência irá buscar na religião cristã a concepção moral da moderação, que influenciará, sobremaneira, os juízos à cerca do lucro e da propriedade.

A propriedade privada era vista como legítima. Contudo esta legitimidade não era absoluta. Ela condicionava-se pelo caráter individualista, que permite ao homem apropriar de bens produtivos garantindo-Ihe sua satisfação, pois através disso pode formar reservas necessárias no caso de futuras eventualidades. Ela é condicionada, também, socialmente, ao assinalar que se deve impedir o direito abusivo de seu possuidor quando implicar atitudes abusivas do proprietário em detrimento do bem estar coletivo.

A influência da moral cristã contribuirá para a noção de justo preço, ou seja, para que as trocas se realizassem com equilíbrio, conforme os interesses das partes negociais envolvidas, é necessário que o preço seja justo. Os escolásticos vão considerar como justo preço aquele valor reduzido que permita ao consumidor adquirir o produto normalmente e ao vendedor receber um preço suficiente pelo seu produto que the interesse a venda e consequentemente garanta-lhe uma vida decente. A noção de justo preço será aplicada ao salário que deve permitir ao operário e a sua família viverem conforme a tradição de sua classe social e os costumes locais. Ao mesmo tempo a noção de justo preço é, também, incorporada no conceito de lucro.

A economia da Idade Média era essencialmente uma economia agrícola e autossuficiente, em que de forma geral a maioria das necessidades da população eram atendidas no próprio feudo. Assim, era natural o papel preponderante da agricultura em relação ao artesanato e ao comércio. 


\section{A EMERGÊNCIA DA ECONOMIA VOLTADA PARA O MERCADO}

"Os anos iniciais do século XVI na Europa assinalam como característica marcante o declínio da estrutura feudal e, concomitantemente, a emergência do sistema capitalista". (HUNT e SHERMAN, 1995, p.32). Neste período ocorreram as mudanças sociais e econômicas que aos poucos foram destravando o caminho para o surgimento, a expansão e a consolidação do capitalismo. O crescimento demográfico constante europeu, o cercamento dos campos utilizados como pastagens comunais inicialmente na Inglaterra, o progresso científico, o movimento migratório paras as cidades estimularam a dissolução dos antigos laços feudais que, ainda, persistiam. Paralelamente nos Estados-nações as correlações das forças políticas alteravam-se. A aliança política entre reis e capitalistas retirou poderes da nobreza feudal em diversas áreas cruciais, como os setores de comércio e de produção, conforme Hunte e Sherman (1995, p.36). É neste cenário que surge a doutrina econômica do Mercantilismo. Segundo Sandroni (1994, p.219):

(...)esta escola, que marca o período compreendido entre os séculos $\mathrm{XVI}$ e XVII, se caracterizava pelos seguintes princípios econômicos: I

- O estado deve expandir o bem estar de sua população, mesmo que afete outros países e colônias; II - A riqueza econômica de uma nação depende da expansão demográfica e do acúmulo de metais preciosos; III - Balança comercial favorável; e IV - Preponderância econômica do comércio e da indústria em relação à agricultura.

Já Rezende (2005) destaca no mercantilismo a prática do intervencionismo estatal na economia. Para esse autor os traços mais marcantes dessa corrente econômica foram: I - O metalismo, ou seja, a prosperidade e a riqueza de um país decorreriam da quantidade de ouro e prata que ele acumulasse; II- O volume das exportações sempre superior às importações; III - Nacionalismo econômico, que consistia no incentivo ao setor secundário nacional; e IV - O colonialismo.

Segundo, ainda, Rezende (2005), o esforço dos países mercantilista na autossuficiência e na produção de manufaturados encontravam dificuldades na obtenção de certas matérias-primas que, por motivos geoclimáticos, só poderiam ser 
produzidas em áreas tropicais. Contudo, este óbice poderia ser contornado caso os países centrais possuíssem colônias. Desta forma, poderia se atingir o objetivo principal da política mercantilista, que era obter metais preciosos, ou então, conseguir explorar mercadorias para sua comercialização lucrativa no mercado europeu.

Portanto, embora não sendo vista como a atividade principal da economia, a agricultura está subjacente no pensamento econômico mercantilista. Além disso, ele emerge nesta doutrina como fator embora não direto, mas importante para a consecução do alcance da política mercantilista.

\section{A AGRICULTURA COMO ÚNICA FONTE DO EXCEDENTE ECONÔMICO E DA RIQUEZA}

No período de transição entre o declínio do feudalismo e a ascensão do capitalismo comercial a visão da função da agricultura no sistema econômica sofre mudanças. $E$ esta mudança no papel da agricultura na economia se dá com a escola econômica Fisiocrata.

Os fisiocratas eram um grupo de economistas franceses cujo principal expoente foi François Quesnay. Para esta escola econômica só a natureza, ou seja, a terra é produtiva com capacidade de multiplicar um grão de feijão em muitos outros grãos. Os setores como a indústria e o comércio, mesmo importantes, realizam, apenas, o transporte e a transformação do produto originário da natureza. Na sua estrutura teórica, dividia a sociedade em três classes: I - A classe produtiva; II - A classe dos proprietários; e III - A classe estéril).

Para Quesnay:

A nação se reduz a três classes de cidadãos: a classe produtiva, a classe dos proprietários e a classe estéril. A classe produtiva é a que faz renascer, pelo cultivo do território, as riquezas da nação, efetua os adiantamentos das despesas com os trabalhos da agricultura e paga anualmente as rendas dos proprietários das terras. Englobam- se no âmbito dessa classe todos os trabalhos e despesas feitas na agricultura, até a venda dos produtos em primeira mão; por essa venda conhece-se o valor da reprodução anual das riquezas da nação. A classe dos 
proprietários compreende o soberano, os possuidores de terras e os dizimeiros. Essa classe subsiste pela renda ou produto líquido do cultivo da terra, que lhe pago anualmente pela classe produtiva, depois que esta descontou, da reprodução que faz renascer cada ano, as riquezas necessárias ao reembolso de seus adiantamentos anuais e à manutenção de suas riquezas de exploração. A classe estéril é formada por todos os cidadãos ocupados em outros serviços e trabalhos que não a agricultura, e cujas despesas são pagas pela classe produtiva e pela classe dos proprietários, os quais, por sua vez tiram sua renda da classe produtiva. (QUESNAY, 1983, p. 258).

Assim, neste trabalho Quesnay apresenta o modelo de fluxo de renda entre esses setores da economia. Os proprietários e os agricultores adquirem produtos e serviços dos outros setores que, por sua vez, retornam essa renda na forma de compra de produtos agrícolas. Considerava que essa circulação da renda retratava uma ordem natural determinada por leis inalteráveis assim como as leis que regem a física.

A partir desta visão, segundo Sandroni (1994, p.141), "os fisiocratas defendiam ampla liberdade econômica, a extinção de todas as taxas e a sua substituição por um tributo único sobre a propriedade e os estado como garantidor da propriedade e da liberdade econômica".

Desta forma pode-se entender que esta doutrina econômica formulou pela primeira vez os princípios do liberalismo econômico. A sua análise econômica centraliza-se na produção, modificando o centro de análise da economia que, até então, privilegiava a atividade comercial. Além disso, colocou a agricultura como a única atividade produtiva e geradora da riqueza e da prosperidade de uma nação.

\section{O DESENVOLVIMENTO AGRÍCOLA NOS CLÁSSICOS: SMITH, MALTHUS E RICARDO}

Adam Smith, autor do livro clássico A Riqueza das Nações, publicado em 1776, começa a deslocar a centralidade da agricultura na análise econômica que ocupava no pensamento dos Fisiocratas. A agricultura, a partir daí, passa a subordina-se ao processo de acumulação econômica do capital de maneira geral. O tema em torno do qual a obra se estrutura está na criação e na expansão da riqueza a qual, segundo ele, decorre do trabalho humano. Assim, não era, apenas, o trabalho agrícola que era gerador de riqueza, mas todo trabalho produtivo, 
inserido na divisão do trabalho e na especialização, que produz um excedente econômico. (CORAZZA e MARTINELL JR., 2002, p.17).

No entanto, Smith afirma a relevância produtiva do trabalho agrícola em relação aos trabalhos artesanal e comercial. Uma vez que o trabalhador do campo produza para a sua subsistência e da sua família, como também, para a lucratividade de seus empregadores e a renda dos proprietários da terra. Ao mesmo tempo, este pensador, considera que 0 trabalho industrial tem a tendência de ser mais produtivo em decorrência do setor industrial se adequar mais facilmente à especialização e á divisão do trabalho. Decorre dessa análise que o excedente econômico não é visto mais como de natureza física, quantitativa, mas como valor de troca ou valor econômico criado pelo trabalho.

Thomas Robert Malthus (1766 - 1834) que viveu no transcurso da Revolução Industrial Inglesa, publica em 1798, sua obra mais conhecida Ensaio sobre o princípio da população. Neste trabalho ele formula sua contribuição mais relevante para a teoria da população. De acordo com Malthus a produção de alimentos se expande em uma progressão aritmética enquanto crescimento demográfica ocorre em progressão geométrica. implicando pobreza e fome de maneira geral. Esse crescimento populacional poderia ser contido através de diversos fatores restritivos como a barreira moral, a miséria, o vício, além de outros condicionantes, entre os quais a guerra, a peste e outras doenças.

Afirma Malthus:

$\{\ldots\}$ Então, adotando meus postulados como certos, afirmo que o poder de crescimento da população é indefinidamente maior do que o poder que tem a terra de produzir meios de subsistência para o homem. A população, quando não controlada, cresce numa progressão geométrica. Os meios de subsistência crescem apenas numa progressão aritmética. Um pequeno conhecimento de números

demonstrará a enormidade do primeiro poder em comparação com o segundo. Por aquela lei da nossa natureza que torna o alimento necessário para a vida humana, os efeitos desses dois poderes desiguais devem ser mantidos iguais. Isso implica um obstáculo que atua de modo firme e constante sobre a população, a partir da dificuldade da subsistência. Esta dificuldade deve diminuir em algum lugar e deve, 
necessariamente, ser duramente sentida por uma grande parcela da humanidade.(...) (MALTHUS, 1996, p. 242).

Para Galbraith (1987, p. 71) "nenhum autor, até então, colocou tão pesadamente a responsabilidade da pobreza sobre os ombros dos próprios pobres como fez Malthus".

Tema de interesse de grandes pensadores da época, a teoria da renda da terra, também, foi objeto de análise por Malthus. Para ele a renda da terra corresponde à parte do produto total que fica com o proprietário da terra depois de todos os pagamentos efetuados com o cultivo da lavoura. Desta forma, a renda da terra se origina do preço superior ao custo de produção dos produtos agrícolas que decorre, por sua vez, de 03 fatores: a qualidade do solo, a peculiaridade do produto agrícola que cria e expande sua própria demanda e a relativa escassez de terras férteis. Para Lenz (1985) Malthus faz um vínculo direto entre a existência de riqueza e a geração de renda da terra ("como dádiva da natureza"), em que a classe proprietária de terra se reveste de importância ímpar na sociedade.

O modelo econômico ricardiano fundamenta-se na análise dos lucros agrícolas em decorrência das peculiaridades dos bens originários da agricultura que podem, ao mesmo tempo, ser utilizados como insumos ou produtos de consumo. Neste modelo, em que predomina a agricultura, há uma visão ampla dos mecanismos que interferem na produção e na distribuição do produto da sociedade, as forças estimuladoras e restritivas do crescimento da economia, assinalam (CORAZZA e MARTINELLI JR, 2002, p.19).

A agricultura assume um papel tão importante que condiciona a economia como um todo, afetando o valor dos alimentos, os salários das indústrias, os investimentos, os lucros e a expansão do produto nacional. Desta forma, o desempenho agrícola será capaz de determinar a tendência do crescimento econômico e, como também, a distribuição da renda nacional entre as classes sociais.

Decorre dessa visão ricardiana o conceito de renda da terra que, para Ricardo, é a parcela do produto originário do cultivo do solo paga ao proprietário para poder explorar produtivamente o solo de sua propriedade. Diferentemente de Malthus, Davi Ricardo considera que a renda da terra origina-se da raridade desse recurso natural. Pois, sendo a terra limitada, com fertilidade variável e com a necessidade de se 
incorporar ao processo produtivo agrícola terras de qualidade inferior faz-se necessário pagar uma renda para poder explorá-la.

\section{O PAPEL SUBORDINADO DA AGRICULTURA}

Com Karl Marx a agricultura passa a desempenhar uma função de subordinação ao processo de acumulação geral do capital.

Segundo este autor:

( ) Na esfera da agricultura, a grande indústria atua de modo mais revolucionário à medida que aniquila o baluarte da velha sociedade, o "camponês", substituindo-o pelo trabalhador assalariado. As necessidades de revolucionamento social e as antíteses do campo são, assim, niveladas às da cidade. No lugar da produção mais rotineira e irracional, surge a aplicação consciente, tecnológica da ciência. A ruptura do laço familiar original de agricultura e manufatura, que envolvia a configuração infantilmente não desenvolvida de ambas, é completada pelo modo de produção capitalista. Mas ele cria, ao mesmo tempo, os pressupostos materiais de uma síntese nova, mais elevada, da união entre agricultura e indústria com base em suas configurações antiteticamente elaboradas. Com a preponderância sempre crescente da população urbana que amontoa em grandes centros, a produção capitalista acumula, por um lado, a força motriz histórica da sociedade, mas perturba, por outro lado, o metabolismo entre homem e terra, isto é, o retorno dos componentes da terra consumidos pelo homem, sob forma de alimentos e vestuário, à terra, portanto, a eterna condição natural de fertilidade permanente do solo. Com isso, ela destrói simultaneamente a saúde física dos trabalhadores urbanos e a vida espiritual dos trabalhadores rurais. Mas, ao destruir as condições desse metabolismo, desenvolvidas espontaneamente, obriga-o, simultaneamente, a restaurá-lo de maneira sistemática, como lei reguladora da produção social e numa forma adequada ao pleno desenvolvimento humano. Tanto na agricultura quanto na manufatura, a transformação capitalista do processo de produção aparece, ao mesmo tempo, como martirológio dos produtores, o meio de trabalho como um meio de subjugação, exploração e pauperização do trabalhador, a combinação social dos processos de trabalho como opressão organizada de sua vitalidade, liberdade e autonomia individuais.(..) (MARX, 1996, p. 133).

Marx considerava fundamental para o desenvolvimento capitalista a criação de um mercado interno que proporcionasse o desenvolvimento da produção comercial com a divisão social do trabalho, inclusive, na produção rural, sustentada na divisão dos 
vários procedimentos de transformação dos produtos in natura extraídos da agricultura para, em seguida, serem transformados em setores industriais próprios, voltando a interagir com o setor agrícola por meio da comercialização das mercadorias, trocando as suas mercadorias por outras de origem rural.

A Figura 1 apresenta uma síntese das transformações que ocorrem na agricultura com o avanço das relações capitalistas no campo.

Figura 1: O processo de penetração do capitalismo no campo

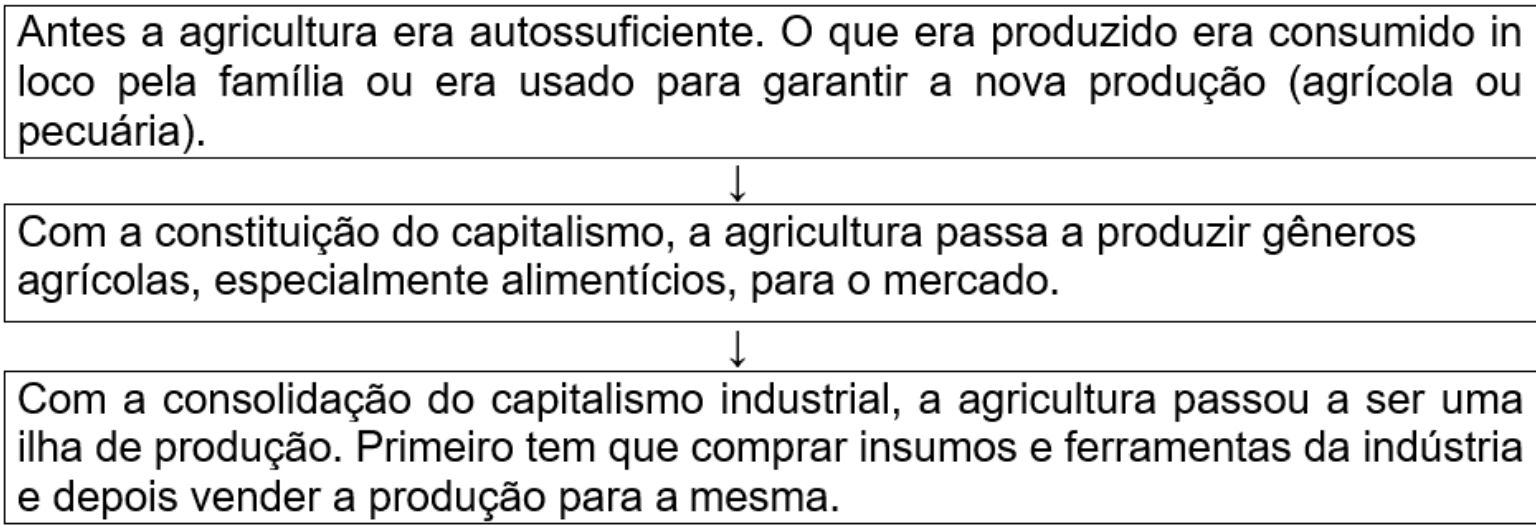

Fonte: Carvalho (2015, p. 27).

Percebe-se, conforme a Figura 1 acima, que o agricultor era autossuficiente, produzia para si e sua família. Agora, comercializa sua produção para a indústria e, em seguida, adquiri outros produtos fornecidos por esse setor industrial. Paulatinamente, o camponês foi perdendo sua autonomia. A grande maioria não conseguiu amolda-se às novas formas de produção e acabou expulso do espaço agrário, indo se concentrar na periferia das grandes cidades em busca de emprego.

Assim, a grande propriedade rural que conseguiu se adequar às novas técnicas, e seguiu o compasso do desenvolvimento da indústria, conseguiu sobressair-se e passou a subordinar a sua produção aos interesses da indústria. Com a expansão e consolidação do capitalismo no campo ocorre 0 aumento da produção e da produtividade $e$ transformações nas relações de trabalho, no espaço como no urbano. Marx conclui que a agricultura passa a desempenhar um papel de subordinação ao capital industrial. (CARVALHO, 2015, p. 27). 
Nesta perspectiva Marx assinala o mecanismo social da renda da terra, uma vez que a agricultura depende do modo de produção do capitalismo. Para Amin e Vergopoulos (1997), a submissão da agricultura transcorre de duas formas. A primeira, de característica econômica, se dá por meio da intervenção do capital dominante, complexo industrial e comercial de alimentos, no processo produtivo agrícola, que irá impor aos produtores do campo a padronização da produção, programas de trabalhos uniformes, padronização de produtos, concentração de redes coletoras de mercadorias, comercialização, entre outros fatores. A segunda forma, é de vertente política, é a alianças de classes entre o capital dominante e os proprietários fundiários. Desta forma acentua-se, cada vez mais, a submissão da agricultura ao capitalismo em nível mundial.

No entanto, Silva (1981, p. 22) pontua que:

(...) a penetração do capitalismo na agricultura encontra barreira na propriedade fundiária. De modo que a propriedade da terra torna-se um monopólio, impedindo o deslocamento de outros capitais para este setor. Esse monopólio assume dois aspectos. De um lado decorre da produção agrícola em determinado solo com determinadas características. De outro lado, ele se dá pela propriedade privada da terra, dispondo dela como quiserem. São esses dois aspectos que geram a renda da terra.

Por sua vez, a renda fundiária desdobra-se em renda diferencial e em renda absoluta. A renda diferencial decorre de seu uso e exploração. Pois o meio de produção terra possui determinadas característica monopolista como sua heterogeneidade, extensão limitada e não reprodutível. Esta renda diferencial pode, ainda, ser derivada em duas. Uma primeira que decorre da diferença de localização e de fertilidade do solo; e uma segunda que provém das inversões de capital e trabalho realizadas no solo. A renda fundiária absoluta deriva do pagamento que o proprietário do solo recebe pela exploração da sua terra pelos capitalistas. Para AQmin e Vergopoulos (1977), a renda fundiária em Marx é um produto da sociedade capitalista como os demais produtos que este modo de produção gera.

Contudo, uma maneira de superar este óbice é através do progresso técnico, o qual conduz a subordinação da própria natureza. Mas esta submissão não se dá por 
completo, pois dificilmente se consegue contrapor-se completamente às ações das forças naturais.

\section{A ABORDAGEM NEOCLÁSSICA: O FIM DA AGRICULTURA COMO SETOR ESPECÍFICO DA ANÁLISE ECONÔMICA}

O pensamento neoclássico irá abandonar a teoria do valor trabalho, a análise estruturada em classes sociais e o conceito de excedente econômico. Nesta perspectiva, a estrutura analítica se dá em torno dos fatores de produção: terra, capital e trabalho. A função de produção neoclássica estrutura-se de forma multiplicativa e com perfeita substitubilidade dos seus componentes: capital, trabalho e terra (recursos naturais). Assim, o desenvolvimento agrícola se dá pela evolução dos fatores de produção, os quais são substituíveis entre si.

No contexto da agricultura, na análise neoclássica as primeiras abordagens sobre o terma surgem a partir da oposição entre produção agrícola das nações desenvolvidas e a pobreza agrária nos países subdesenvolvidos. Os componentes a diferenciar seriam as inovações tecnológicas assumidas pelos primeiros e a contínua utilização de fatores produtivos tradicionais pelos segundos. Nesta perspectiva, destaca-se a contribuição de Thedore W. Schultz sobre a teoria dos altos rendimentos dos insumos.

Para este autor, a eficiência do processo produtivo rural dos países desenvolvidos se deve a modernização do campo e, no caso dos países subdesenvolvidos, a pobreza rural decorre da baixa produtividade marginal dos fatores de produção tradicionais como terra e mão-de-obra, a desestimular a reinversão produtiva dos agricultores.

Segundo ele:

$\mathrm{Na}$ melhor das hipóteses, há pouca probabilidade de crescimento proveniente da agricultura tradicional, porque os agricultores já esgotaram as possibilidades de produção lucrativas proporcionadas pelo nível de conhecimento de que dispõem. Melhor distribuição de recursos, mais poupança, e investimentos restritos apenas aos fatores de produção que vêm empregando, não farão muito para ajudar o crescimento. A despeito de tudo que tem sido escrito sobre como melhorar a combinação dos fatores nas comunidades pobres, são 
pequenos os acréscimos na renda real a serem obtidos por meio de uma distribuição melhor dos fatores existentes. Mesmo que tal economia de tostão fosse uma máquina misturadora perfeita na distribuição de todos e de cada. Um dos fatores a sua disposição, a comunidade permaneceria pobre. Segue-se uma conclusão semelhante, com respeito ao crescimento a ser obtido com acréscimos no estoque de tais fatores. Constituem fontes caras de renda adicional e, por essa razão, oferecem pouca oportunidade para o crescimento. O significado disso, é que a agricultura permanece miserável em tais circunstâncias. (SCHULTZ, 2005, p. 14).

$\mathrm{Na}$ contribuição de Schultz a agricultura é considerada fonte de crescimento econômico. Contrapondo-se àqueles economistas que condicionavam a expansão das atividades econômicas a partir do setor industrial.

\section{A VISÃO KEYNESIANA: A IRRELEVÂNCIA TEÓRICA DA AGRICULTURA}

John Maynard Keynes publica, em 1936, a sua obra mais conhecida e discutida, A teoria Geral do Emprego, do Juro e da Moeda. O autor, neste trabalho, enfatiza o caráter geral da sua teoria, contrapondo-se aos postulados dos autores clássicos que, segundo Keynes, só se aplica a um caso especial, o de equilíbrio. (KEYNES, 1996, p.43).

A teoria de Keynes tem como base fundamental a demanda efetiva que representa o nível de produto que os empresários pretendem obter do emprego de determinada quantidade de trabalhadores. Em outros termos, é o ponto em que se iguala a função demanda com a oferta agregada. (KEYNES, 1996).

De acordo com Keynes:

As grandes linhas da nossa teoria podem expressar-se da maneira que se segue. Quando o emprego aumenta, aumenta, também, a renda real agregada. A psicologia da comunidade é tal que, quando a renda real agregada aumenta, o consumo agregado também aumenta, porém não tanto quanto a renda. Em consequência, os empresários sofreriam uma perda se o aumento total do emprego se destinasse a satisfazer a maior demanda para consumo imediato. Dessa maneira, para justificar qualquer volume de emprego, deve existir um volume de investimento suficiente para absorver o excesso da produção total sobre o que a comunidade deseja consumir quando o emprego se acha em determinado nível. A não ser que haja este volume de investimento, as 
receitas dos empresários serão menores que as necessárias para induzilos a oferecer tal volume de emprego. Daqui se segue, portanto, que, dado o que chamaremos de propensão a consumir da comunidade, o nível de equilíbrio do emprego, isto é, o nível em que nada incita os empresários em conjunto a aumentar ou reduzir o emprego, dependerá do montante de investimento corrente. O montante de investimento corrente dependerá, por sua vez, do que chamaremos de incentivo para investir, o qual, como se verificará, depende da relação entre a escala da eficiência marginal do capital e o complexo das taxas de juros que incidem sobre os empréstimos de prazos e riscos diversos. (KEYNES, 1996, p. 62).

$\mathrm{Na}$ teoria Keynesiana, como se observa no texto acima, a agricultura deixa de ser caracterizada como categoria de análise especifica. Pois, Keynes parte da compreensão de que o sistema capitalista é profundamente instável. E nestas crises o estado deve intervir com investimentos suficientes para se adequar e gerar a demanda necessária. Assim, a agricultura não é tratada especificamente, mas é considerada, apenas, como um dos componentes da demanda agregada. Decorre daí que as medidas devem ser tomadas visando elevar a demanda efetiva como um todo e, não só, um determinado segmento específico da economia, como a agricultura.

\section{O DOMÍNIO DA AGRICULTURA PELAS GRANDES CORPORAÇÕES AGROALIMENTARES}

A partir das décadas de 1970 e 1980 as políticas Keynesianas, até então dominantes nas principais economias capitalistas, são substituídas pelas medidas econômicas de caráter neoliberal que visavam liberar o capital das restrições impostas pelo Estado de bem estar social. De forma a revigorar as condições de acumulação do capital.

O neoliberalismo é uma versão atualizada da doutrina liberal a partir do arcabouço teórico da economia neoclássica. Trata-se de um conjunto de ideias econômicas que prega o estado mínimo na economia, ou seja, a não participação do estado na atividade econômica; o livre fluxo dos capitais internacionais e o mercado comercial livre em termos mundiais.

As políticas neoliberais são postas em prática, inicialmente, na Inglaterra por Margareth Tactcher (1979) e por Ronald Reagan nos EUA (1981). A partir desses 
países as políticas neoliberais se expandem por diversos países consolidando a sua hegemonia mundial.

$\mathrm{Na}$ agricultura adoção de políticas neoliberais concretizou-se com a sua reestruturação com base na produção de commodities, nas bolsas de mercadorias e futuros e nas empresas monopolistas internacionais. A produção de commodities visou a transformação da produção rural em mercadorias voltadas para atender a demanda mundial. A produção de alimentos estava voltada para quem tivesse dinheiro para adquiri-lo no mercado mundial. Já não se visava atender a um mercado nacional. Destacando-se entre as principais commodities o trigo, a soja, o milho, o arroz, o algodão, o café, o boi gordo, entre outras.

As bolsas de mercadorias e futuros constituíram-se no centro de referência dos preços internacionais das commodities. A bolsa Mercantile Exchange (CME), mais conhecida como a bolsa de Chicago, é a principal bolsa mundial do comércio de alimentos. Ela participa do CME Group que possui o maior e mais variado mercado de derivativos mundial, onde são estabelecidos os preços de diversas commodities como a soja, o trigo, o boi gordo, o milho e outras.

O quadro de reestruturação da agricultura completa-se com a formação de grandes empresas agroalimentares em nível mundial, que passaram a controlar a produção de commodities agrícolas. No âmbito internacional quatro empresas dominam, praticamente, o mercado mundial de alimentos: Cargill, Acher Daniels Company (ADM), Bunge Limited e a Louis Dreyfus Group. Estas empresas agem coordenadamente nos mercados internacionais através de fusão, associação, aquisição, entre outros mecanismos. (OLIVEIRA, 2015, p. 240).

$\mathrm{Na}$ agricultura as consequências das políticas neoliberais foram:

a) As empresas agroalimentares passaram a controlar o comércio mundial de produtos agrícolas, principalmente o de grãos, concomitante ao domínio dos mercados nacionais;

b) Concentração e desnacionalização de empresas agroindustriais em diversos países;

c) Padronização da dieta alimentar de consumo mundial; 
d) Eliminação das políticas estatais de proteção da agricultura e dos agricultores;

e) O controle pelo grande capital das novas técnicas a serem utilizadas na produção agrícola;

f) Incursões do capital internacional para o controle da água potável em todo o mundo. (STEDILE, 2010).

Os Quadros 1 e 2 apresentam as principais características da agricultura antes e após o domínio neoliberal. Neles se constatam as grandes diferenças das linhas mestras plicadas a agricultura em termos gerais.

Quadro 1: Políticas agrícolas anteriores ao neoliberalismo

Produção camponesa

Sistema de estoques governamentais

Subsídios agrícolas

FAO (órgão mundial)

Fonte: adaptado de Oliveira (2015, p. 240)

No plano da regulação mundial da agricultura a OMC substitui a FAO como entidade de resolução das disputas comerciais entre países. Com a finalidade de dar um novo enfoque as decisões comerciais entre países.

Quadro 2:Políticas agrícolas neoliberais

Posição contrária aos subsídios agrícolas

Redução dos estoques governamentais de alimentos

Substituição dos estoques governamentais por estoques de empresas

monopolistas internacionais.

Criação da OMC

Fonte: Adaptado de Oliveira (2015, p. 240)

Assim, a política neoliberal na agricultura se dissemina no setor rural com a mundialização da produção agropecuária. Pois este processo, sob o domínio do capital financeiro, necessita de total liberdade para se expandir. 


\section{CONSIDERAÇÕES FINAIS}

Nas primeiras análises econômicas, a agricultura era considerada uma atividade econômica superior às outras em decorrência de prover a alimentação necessária à população. Este destaque à agricultura se refletiu no plano teórico, sendo vista como uma ordem natural que regia a economia.

Com a teoria fisiocrata a ordem natural do pensamento econômico dá lugar a ordem de mercado. A terra e seus produtos são transformados em mercadorias sob a égide da valorização do capital e da lei do valor.

Com os pensadores clássicos a terra perde a sua relevância inconteste e subordinase ao comando do capital industrial, de modo que se desloca a origem do excedente da terra para o trabalho. No entanto, a agricultura, ainda, consegue manter o domínio nas ideias econômicas do período.

A teoria econômica neoclássica passa a considerar o setor agrícola como os demais setores como o do trabalho e o do capital. A agricultura perde sua especificidade, assumindo um papel secundário, em decorrência desses autores já vislumbrarem o domínio da indústria na economia.

Com o advento do neoliberalismo há o domínio do capital financeiro e de suas grandes empresas agroalimentares. E a mundialização da agricultura.

Desta forma, pode-se concluir que, ao longo da evolução da ciência econômica, a agricultura sempre se manteve presente nos principais textos econômicos. De maneira diferenciada e, também, específica, acompanhando o papel que ela exerceu na economia no transcorrer de seu desenvolvimento.

\section{REFERÊNCIAS}

AMIN, Samir; VERGOPOULOS, Kostas. A questão agrária e o capitalismo. Rio de Janeiro: Paz e terra, 1977. 179 p. 
CARVALHO, Joelson Gonçalves. Economia agrária. Volume único. Rio de Janeiro: Fundação Ceciere, 2015, 246 p.

CORAZZA, Gentil; MARTINELLI JR, Orlando. Agricultura e questão agrária na história do pensamento econômico. Revista Teoria e Evidência Econômica, Passo Fundo, v.10, n.19, p.09-36, Nov.2002.

GALBRAITH, John Kenneth. O pensamento econômico em perspectiva: uma história crítica. São Paulo: Pioneira: editora da Universidade de São Paulo, 1989. 289 p. ( coleção novos umbrais).

HUNT, E. K; SHERMAN, Howard, J. História do pensamento econômico. 13ạ. ed. Petrópolis: Vozes, 1995. 218 p.

KEYNES, John Maynard. A teoria geral do emprego, do juro e da moeda. São Paulo: Ed. Nova Cultura, 1996, 328 p.

LENZ, Maria Heloisa. A teoria da renda da terra: Ricardo e Malthus. Ensaios FEE, Porto Alegre, v.6, n.1, p.81-104. 1985.

MALTHUS, Robert, T. Princípios de economia política - consideração sobre sua aplicação prática - ensaios sobre a população. São Paulo: Editora Abril Cultural, coleção os economistas, 1996, 382 p.

MARX, Karl. O capital, volume 1.São Paulo: Editora Nova Cultural Ltda, 1996, 381 p.

OLIVEIRA, A. U. A mundialização do capital e a crise do neoliberalismo: o lugar mundial da agricultura brasileira. Geousp - Espaço e Tempo (Online), v. 19, n. 2, p. 229-245, ago. 2015. ISSN 2179-0892.

QUESNAY, François. Análise do quadro econômico. Apresentação de Roberto Campos. Tradução de João Guilherme Vargas Neto. São Paulo, Abril Cultural, 1983, coleção Os economistas. 
REZENDE FILHO, Cyro de Barros. História econômica geral. 8ª ed. São Paulo: Contexto, 005. 355 p.

SANDRONI, Paulo. Novo dicionário de economia. 4aㅗ ed. São Paulo: Best Seller, 1994. $375 \mathrm{p}$.

SCHULTZ, Theodore, W. Fatores de produção encobertos sob o título de “mudanças tecnológicas." Revista Brasileira de Inovação, Campinas, v. 4, n. 1, janeiro/junho 2005.

SILVA, José Graziano. O que é questão agrária. 4a ed. São Paulo: Brasiliense, 1981. $45 \mathrm{p}$.

STEDILE, J. P. A natureza do desenvolvimento capitalista na agricultura. MST, 2010. Disponível em: <http://base.d-p-h.info/pt/fiches/dph/fiche-dph-8244.html>.

Enviado: Agosto, 2020.

Aprovado: Agosto, 2020. 